\title{
Impact of a "vegetables first" approach to complementary feeding on later intake and liking of vegetables in infants: a study protocol for a randomised controlled trial
}

\author{
Jeanette P. Rapson ${ }^{1}$, Pamela R. von Hurst', Marion M. Hetherington ${ }^{2}$ and Cathryn A. Conlon ${ }^{1 *}$ (D)
}

\begin{abstract}
Background: Vegetables as first complementary foods for infants may programme taste preferences that lead to improved vegetable intake in children. Yet few studies have investigated the impact of a "vegetables first" approach to complementary feeding, especially in New Zealand. The purpose of this randomised control trial is to investigate the effect of starting complementary feeding with vegetables only on infants' later intake and liking of vegetables, compared to those starting with fruit and vegetables.

Methods/design: One-hundred and twenty mother-infant pairs living in Auckland, New Zealand, will be randomised to receive either vegetables only (intervention) or fruit and vegetables (control) for 28 days, starting from the first day of complementary feeding at around 4-6 months of age. Infants will be presented with a brassica (broccoli), followed by a green leafy vegetable (spinach) and sweet fruit (pear) at 9 months of age. The primary outcome measures of intake of each food will be assessed using a weighed food diary. Secondary outcome measures of overall intake, liking and wanting of vegetables will be assessed using a food frequency questionnaire, liking tool and video coding tool, respectively, at 9, 12, and 24 months of age. Infant growth and iron status will be assessed as part of health screening and monitoring at baseline, post intervention and 9 months of age. Other biological samples to be collected include infant stool samples, vitamin D (mother and infant), iron status (mother), and mothers' diet.
\end{abstract}

Discussion: This randomised, controlled trial will be the first to our knowledge to investigate a "vegetables first" approach to complementary feeding on infants' liking and intake of vegetables in New Zealand. Comparison against standard practice (fruit and vegetables as first foods) should complement other trials underway, such as the Baby's First Bites and Nordic OTIS trial. Results may contribute to the evidence supporting complementary feeding guidelines in New Zealand and worldwide.

Trial registration: Australian New Zealand Clinical Trial Registry ACTRN12619000737134. Registered on 16 May 2019.

Keywords: Infants, Weaning, Introducing vegetables, Food preference, Vegetable intake

\footnotetext{
* Correspondence: c.conlon@massey.ac.nz

'School of Sport, Exercise and Nutrition, Massey University, Auckland, New

Zealand

Full list of author information is available at the end of the article
}

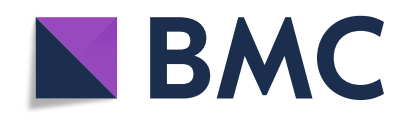

(- The Author(s). 2021 Open Access This article is licensed under a Creative Commons Attribution 4.0 International License, which permits use, sharing, adaptation, distribution and reproduction in any medium or format, as long as you give appropriate credit to the original author(s) and the source, provide a link to the Creative Commons licence, and indicate if changes were made. The images or other third party material in this article are included in the article's Creative Commons licence, unless indicated otherwise in a credit line to the material. If material is not included in the article's Creative Commons licence and your intended use is not permitted by statutory regulation or exceeds the permitted use, you will need to obtain permission directly from the copyright holder. To view a copy of this licence, visit http://creativecommons.org/licenses/by/4.0/. The Creative Commons Public Domain Dedication waiver (http://creativecommons.org/publicdomain/zero/1.0/) applies to the data made available in this article, unless otherwise stated in a credit line to the data. 


\section{Background}

Children are encouraged to eat plenty of different vegetables daily in order to meet a range of nutrient requirements for growth and development, immune function, and digestive health $[1,2]$. Children with adequate vegetable intake may have a lower risk of obesity [3] and cardiovascular disease in adulthood [4,5], and be more likely to develop healthy eating habits for life $[6,7]$. Yet children's vegetable consumption remains low worldwide [ $8-12$ ]. In the UK, only $14 \%$ of children ( $5-7$ years) eat the recommended five or more portions of vegetables and fruit per day [12]. Vegetable intake in the US is similarly low, with the FITS study finding $30 \%$ of children 12 months or older not consuming any vegetable servings on a given day [13]. New Zealand children (2-4 years) are doing better but intakes are still inadequate, with $46.1 \%$ and $71.2 \%$ of children consuming enough vegetables and fruit, respectively [10].

Reasons for poor vegetable consumption may relate to many factors, including a dislike of bitter taste and poor access [13-15]. Infants have an innate preference for sweetness since breastmilk is sweet and may find bitter taste, such as in dark leafy greens, particularly difficult to accept [16-18]. Meanwhile, children from food insecure households may have an additional challenge of accessing a variety of vegetables [19]. Eurostat data found $5.5 \%$ of UK households with children were unable to afford meat, fish, or a vegetarian alternative every second day [20]. In the US, an estimated $14 \%$ of US families with children experienced food insecurity in 2018 [21]. Similarly, although most New Zealand children live in food-secure households, a substantial number do not (19\%) [22] and so are less likely to have vegetables purchased and offered to them [23].

It is known that offering infants a variety of vegetables from the start of complementary feeding may promote liking through familiarisation and facilitate intake throughout childhood [24-26]. However, many infants receive fruit and sweet tasting vegetables (e.g. pumpkin, sweet potato) as their first foods [27, 28]. Furthermore, most commercial infant foods are largely fruit or sweet/ starchy vegetable based [29-31]. In a sample of traditionally spoon fed New Zealand infants $(n=628), 1 \%$ received "only fruits, no vegetables", 17\% "mainly fruits, some vegetables", $46 \%$ "half fruit, half vegetables", and $4 \%$ "only vegetables, no fruits" when solids were first introduced; just over half were consuming iron-rich foods (meat or infant cereal) at 6 months of age [32]. A recent systematic review of practices to promote vegetable acceptance in the first three years of life concluded that introducing vegetables at the beginning of complementary feeding, giving a different type of vegetable every day and ensuring repeated exposure to the same vegetable following an interval of a few days are the most promising strategies to promote vegetable intake in early childhood [25].

The prioritisation of vegetables only from the start of complementary feeding is known as a "vegetables first" approach to complementary feeding. Only a handful of studies investigating the effects of this approach have been published, with none in New Zealand [33-37]. Barends et al. compared the effects of repeated exposure and starting complementary feeding with vegetables only across four different treatment groups over 18 days. They found that starting complementary feeding with vegetables, but not with fruits, may promote vegetable acceptance and that liking correlated positively with intake. Their follow-up study [35] suggested that starting complementary feeding with vegetables only results in higher daily vegetable consumption until at least 12 months of age; however, further investigation was needed on how to maintain this effect until 24 months of age. Three other studies suggest vegetables as first foods may improve vegetable acceptance later, at least in the short term [33, 36-39]. However, comparability of findings remains limited due to considerable variability in study designs, small sample sizes, and/or poor ecological validity (e.g. conducting trials in the laboratory rather than the home environment). Standardisation across studies could be improved with the use of recent development and validation of tools to assess vegetable liking, such as the Feeding Infants: Behaviour and Facial Expression Coding System (FIBFECS) [40] or an inhome adapted elaborate method for liking tool [41].

Historically, most guidelines on complementary feeding have included vegetables as first complementary foods but alongside fruit and iron-rich foods without a prescribed sequence [1]. The systematic evidence compiled by the UK Public Health England and Scientific Advisory Committee on Nutrition (SACN) [42] however has informed the current NHS recommendations to give a single vegetable and fruit as first foods [43]. While there may be enough evidence to start recommending vegetables as first complementary foods, there is still a need for more longitudinal randomised controlled trials (RCTs) [24, 38, 44, 45]; especially those comparing infants receiving vegetables only to standard practice. Two other trials examining the effects of providing vegetables as first foods on vegetable acceptance are in progress, including the Baby's First Bites (BFB) trial in the Netherlands and the OTIS Nordic trial. In the BFB, infants are randomised to receiving, with or without a positive feeding programme, either fruits and a sweet vegetable or a variety of vegetables. However, all infants start complementary feeding with rice-flour porridge and then vegetables as their first tastes [45]. The Nordic OTIS trial is comparing effects of the recommended, Swedish complementary diet (i.e. starting with baby 
cereals, commercially available baby foods) to one based on Nordic foods (i.e. increased plant foods including fruit and vegetables and reduced sweets, dairy and meat) on food acceptance [44]. Infants in the Nordic group are systematically introduced to fruits (e.g. apples, raspberry, buckthorn/lingonberry, cranberry) and vegetables (green peas, cauliflower, turnip, daikon) from the start of the intervention, rather than vegetables only.

RCTs are one of the most rigorous ways to establish cause-effect relationships between treatment and outcomes [46], and RCT data is a gold standard for translating evidence into practice [47]. Our RCT will test the hypothesis that exposure to vegetables only during the first 4 weeks of complementary feeding increases later intake and liking of vegetables in infants, compared to a control group of fruit and vegetables. If this is supported, our results could contribute to the evidence for recommendations for a "vegetables first" approach to complementary feeding in New Zealand and beyond.

\section{Hypothesis}

Exposure to vegetables only during the first 4 weeks of complementary feeding increases later intake and liking of vegetables in infants, compared to a control group which includes both fruit and vegetables.

\section{Aim}

The overall aim of this study is to determine whether exposure to vegetables only during the first 4 weeks of complementary feeding increases later intake and liking of vegetables in infants, compared to a control group which includes both fruit and vegetables.

\section{Methods/design}

This study is designed as a randomised controlled trial comparing two parallel groups following either a "vegetables first" approach to complementary feeding or standard practice of feeding fruit and vegetables. This involves a 4-week intervention period starting from the beginning of complementary feeding (between 4 and 6 months old), with the primary endpoint of vegetable intake at 9 months of age (Fig. 1). The duration of the intervention targets the sensitive period for taste development [48], is logistically feasible, and allows for a timely progression to other foods and textures (e.g. mashed) that is expected by around 7 months. An endpoint of 9 months old aims to capture effects over time without significant loss to follow-up, and enables the study foods to be retested in an age-appropriate form before infants have transitioned to family foods at 12 months of age.

\section{Participants}

Mother-infant pairs (4 to 6 months old) living in Auckland will be invited to register on the study website (www.vegesfirststudy.co.nz) [49] advertised on social media, email, and community notice boards. Based on the findings of Barends and colleagues [35], we calculated that 65 participants (a minimum of 52 participants, and allowing for a $20 \%$ potential dropout rate) would be required for each arm of the trial to demonstrate a clinically significant difference at $80 \%$ power and $5 \%$ statistical significance. Power calculations used a 21-unit difference of vegetable intake (grammes) between intervention group and control, and a mean standard deviation of 43 and 29 units, respectively. The sample size was calculated using the formula below [50]:

$$
\mathrm{N}=2 \alpha^{2} \mathrm{~K} /\left(\mu_{2}-\mu_{1}\right)^{2}
$$

where $\mathrm{N}$ is the sample size required per group, $\mathrm{SD}$ is the pooled standard deviation, $\alpha$ is the $\mathrm{SD}, \mathrm{K}$ is the constant (7.9 denotes $80 \%$ power and $5 \%$ significance), and $\left(\mu_{2}-\right.$ $\left.\mu_{1}\right)$ is the difference in vegetable intake (grammes) between groups.

\section{Inclusion and exclusion criteria}

Infants will be eligible for this study if they are born term (37 weeks or greater), of normal growth/weight, and have no known food allergies, chronic diseases, or medical conditions. Infants must not have started complementary feeding and must live in Auckland. Mother's proficiency in English is needed given the requirement to complete assessment tools as part of the secondary outcomes. Participants will be excluded if they demonstrate repeated non-adherence to key study procedures or are not able to complete the 4-week intervention period.

\section{Setting}

The study, data collection and analyses will take place in Auckland, New Zealand, from May 2019 to October 2021. Auckland is the major commercial city of New Zealand, with an ethnically diverse population of 1.6 million and around 21 thousand child births recorded in 2018 [51].

\section{Infant foods}

Freeze-dried infant foods are specifically developed for the study by the researchers. According to study specifications, these are manufactured by FreshAs ${ }^{\circ}$ who specialise in the production of high-quality freeze-dried vegetables and fruits and are based in Auckland, New Zealand. Vegetables and fruits are selected based on availability, infant nutrition guidelines, total sugar content per $100 \mathrm{~g}$, and colour. A Dietitian and Speech and 


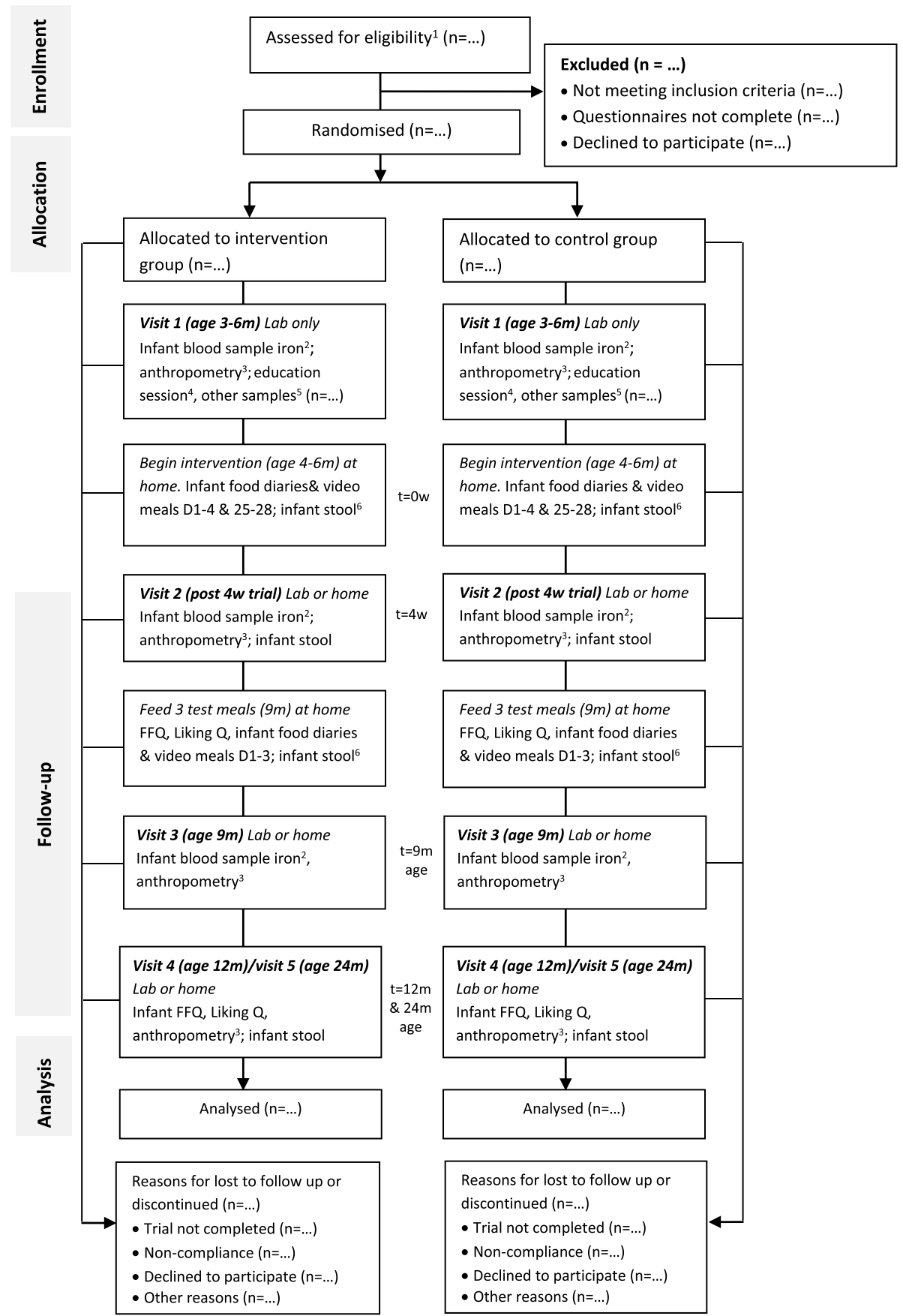

Fig. 1 Schematic diagram of study design. 'Questionnaires: eligibility, demographics, baby eating behaviours, and pregnancy/lactation dietary questionnaires. ${ }^{2}$ Blood biomarkers: serum ferritin, C-reactive protein (CRP), and haemoglobin. ${ }^{3}$ Weight, head circumference, and length. ${ }^{4}$ Includes delivering all study materials, protocol instructions, and information on complementary feeding. ${ }^{5}$ Blood samples to assess the status of mother's iron/vitamin D and infant's vitamin D. ${ }^{6}$ Infant stool sample collected by mother 1 week or less before infant receives the first intervention food/ test meal. Lab, laboratory (Massey University Human Nutrition Research Unit); D, day; w, week; m, month; t, time-point; FFQ, food frequency questionnaire; Q, questionnaire

Language Therapist who specialises in child feeding and development will conduct recipe testing in the laboratory. This confirms that to reconstitute the powders into age-appropriate infant purées, each sachet requires the addition of $50 \mathrm{ml}$ of water (except potato and green bean which require $80 \mathrm{ml}$ ). The food is then heated in the microwave for three 20-s intervals, stirred in between, and then cooled for $10 \mathrm{~min}$ until it is at a safe 
temperature for infants to consume. Final instructions are provided on recipe cards to participants.

The foods provided to the intervention group will be less sweet than controls $(<4 \mathrm{~g}$ total sugar per $100 \mathrm{~g})$ and made from vegetables only (Table 1 ). The control group receives foods that will be sweeter than intervention ( $>4$ $\mathrm{g}$ total sugar per $100 \mathrm{~g}$ ) and fruit based, resembling commercial infant foods that are currently available on the market. Following nutrition guidelines, the study will provide a range of different coloured vegetables, including green, purple, white, and orange. However, it will not be possible to provide an orange-coloured food for the intervention group due to limitations to the freezedrying method and high sweetness profile of available orange-coloured vegetables. Therefore, the intervention group will be offered a second green food, named "Kākāriki", which is the Māori translation for green and so should resonate with New Zealand families.

At baseline, mothers will receive enough food to provide up to three meals per day for the duration of the intervention and will be able to access additional sachets from the Massey University Human Nutrition Research Unit (HNRU) as required. To ensure infants meet iron intake requirements while participating in the study, mothers with an infant starting complementary feeding at 6 months of age will be especially encouraged to provide their own meat (beef, fish, or chicken) during the intervention following recipe cards and videos provided.

\section{Feeding protocol}

Mothers will determine the timing of meals according to their own schedule. However, they will feed the foods according to a prescribed recipe and colour rotation to improve standardisation and ensure infants are exposed to a variety of flavours (Fig. 2). On recording days (the first and last 4 days) mothers must only provide one colour per day, starting with green. On other days, colours rotate per meal. No meat is provided during the first 4 days to standardise infants' very first tastes. To cater to individual infant needs, mothers can provide as many meals as they need per day.

The rotation order of foods offered for the intervention group is determined by sugar content, starting with the first food containing the lowest sugar per $100 \mathrm{~g}$. This should help to expose infants to more bitter flavours first. The order is matched to the intervention group to improve standardisation and ensure vegetables, such as spinach, will be introduced at the same time where possible. Instructions on feeding style and environment will be provided, for example, "let baby lead", "use a spoon", and "choose a quiet time without distractions". At 9 months of age, each group will be offered a brassica (broccoli), green leafy vegetable (spinach) then sweet fruit (pear) over 3 consecutive days (one per day). These will be labelled meal A, meal B, and meal $\mathrm{C}$, respectively. Infants should not have had solid food within $1 \mathrm{~h}$ prior to trying the meal. Assessment of intake of each food should determine whether a "vegetables first" approach to complementary feeding results in higher intake of a brassica or green leafy vegetable at 9 months of age compared to a control group.

\section{Education session}

To standardise the feeding sessions as much as possible, all mothers will receive a 40-min education session on appropriate infant feeding practices during their first visit, delivered by the primary investigator who is also a New Zealand registered Dietitian. Topics include identifying the signs of developmental readiness to start complementary feeding, responsive feeding, and appropriate breast/formula milk feeding. Instructions for the study protocol and food diary will also be discussed in detail. A series of educational resources, including three infant feeding fridge magnets designed for the study will be provided during the session and mothers will be encouraged to visit the study website to view additional resources. After completion of the 4-week intervention, all mothers receive the Ministry of Health Eating for Healthy Babies and Toddlers/Ngā kai tōtika mō te hunga köhungahunga [52] and Beef and Lamb New Zealand Fuelled by Iron [53] pamphlets to assist infants' transition to family foods.

\section{Randomisation, blinding, and concealed allocation}

Eligible and consented mother-infant pairs will be randomly allocated to either the intervention or control

Table 1 Infant foods allocated to the intervention and control group

\begin{tabular}{lll}
\hline Food name & Food ingredient (\%) & \\
\cline { 2 - 3 } & Intervention group & Control group \\
\hline Green purée & Spinach (80\%), potato (20\%) & Apple (90\%), spinach (10\%) \\
White purée & Potato (100\%) & Pear (100\%) \\
Purple purée & Beetroot (70\%), potato (30\%) & Pear (98\%), beetroot (2\%) \\
Orange purée & Not applicable & Pumpkin (100\%) \\
Kākāriki purée & Green bean (100\%) & Not applicable \\
\hline
\end{tabular}

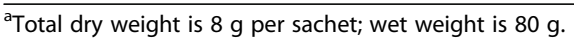




\section{Intervention}

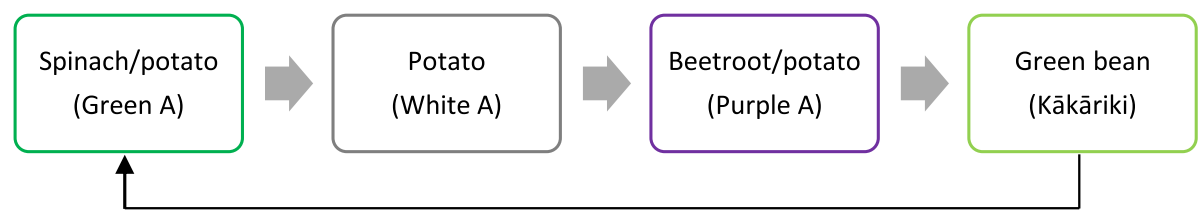

Control

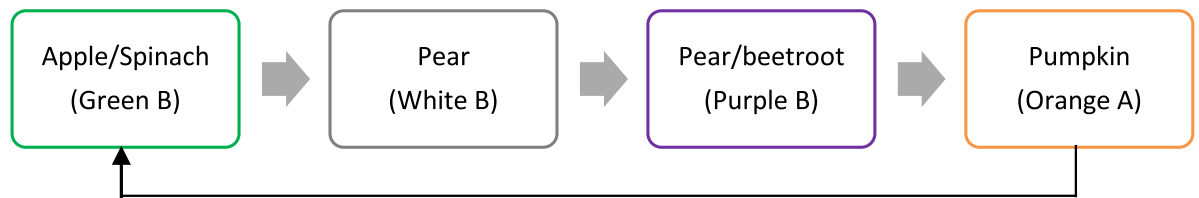

Fig. 2 Food rotations for intervention and control group, either per day (recording days) or per meal (other days). Foods will be labelled by colour and none list the ingredients but mothers are reassured that the foods align with New Zealand infant feeding guidelines. The code A or B act as identifiers for researchers

group, having been stratified by infant gender and using a random number generator by the research trials manager who is not involved in the study design and outcome analysis. In accordance to block randomisation with a 1:1 allocation, for every block of eight participants, four will be allocated to each arm of the trial, with the block size concealed until the primary endpoint is analysed. Allocation concealment will be ensured, as the release of the randomisation code occurs only until the participant has been recruited into the trial, which is after consent and baseline measurements have been completed. After assignment, researchers will not be blinded given their necessary involvement in the food product development and subsequent familiarity with food characteristics (e.g. colour). While participants will be provided with an information sheet that lists all the types of fruit and vegetables included on the study, they will be blinded to the specific foods allocated to them as foods are labelled generically (e.g. "Green A" rather than "spinach/potato"). They will also be unaware of the RCT design, so do not know specific differences between feeding regimes. In an emergency where breaking of the study blind is needed, plans are in place for the principal investigator to reveal the treatment assignment for a given participant.

\section{Data collection}

Mothers will be emailed the links to the online demographics, baby behaviour, and pregnancy/lactation food frequency questionnaires to complete at home before their first visit to the HNRU at which other baseline data (infant anthropometry and blood samples) will be collected. The 4-week intervention and primary data collection (mother reported infant vegetable liking and intake, video-recorded meals) will take place in the infant's home environment from May 2019 to October 2021. Follow-up data (anthropometry and/or blood samples) will be collected at 9, 12, and 24 months of age at the HNRU; home visits will be available as required. In the instance where visits are not possible, mothers will be asked to provide current infant growth measurements (following standardised instructions given by the researcher) and food diaries by email or post. Virtual meetings using Zoom or Skype will be available for additional support. Additional child vegetable/fruit liking and food frequency questionnaires will be completed by mothers at home when their infant is 9,12 , and 24 months old. To the extent possible, we will continue to collect data for all outcome measures for participants who discontinue or deviate from the intervention protocols, while anticipating and planning for missing data. Given the potential for this cohort to provide valuable data for future early life nutrition research, additional outcome measures will be collected. These include mothers' iron status/vitamin D status (at baseline), infants' vitamin D status (at baseline), and infant stool samples for microbiota analysis (pre- and post-4-week intervention, and all follow-ups). Such data may be useful to assess maternal iron status 6 months post-partum or infant vitamin D status and links to the microbiome. Table 2 outlines the primary study outcome measures and testing methods. Figure 3 provides the schedule of enrolment, intervention, and assessment.

\section{Weighed food diary}

Mothers will complete a 4-day weighed food diary during the first and last 4 days of the 4-week intervention to primarily measure infant food intake (grammes). In alignment with other studies [33-39, 55-57], this will involve weighing the food before and after consumption 
Table 2 Summary of the study outcome measures and methods

\begin{tabular}{|c|c|}
\hline Variables & Method \\
\hline \multicolumn{2}{|l|}{ Primary outcomes } \\
\hline \multirow[t]{3}{*}{ Vegetable liking } & Liking tool (Appendix A). Completed by mother at home \\
\hline & Rate of acceptance video coding tool. Mother video-records meals. Independent researcher codes infant behaviours \\
\hline & Child vegetable and fruit liking questionnaires. Completed online by mother \\
\hline \multirow[t]{2}{*}{ Vegetable intake } & Weighed food diary. Completed by mothers at home \\
\hline & FFQ. Completed online by mother \\
\hline \multicolumn{2}{|l|}{ Blood analysis ${ }^{a}$} \\
\hline Infant iron studies ${ }^{b}$ & "Heel prick" test by phlebotomist at Massey University or home \\
\hline Infant vitamin D & "Heel prick" test by phlebotomist at Massey University or home using Whatman card \\
\hline $\begin{array}{l}\text { Mother iron/ } \\
\text { vitamin D }\end{array}$ & Venous blood sample collection by phlebotomist at Massey University \\
\hline \multicolumn{2}{|l|}{ Other measures } \\
\hline $\begin{array}{l}\text { Infant } \\
\text { anthropometry }\end{array}$ & $\begin{array}{l}\text { Head circumference: paper measuring tape, widest part of head, three measures, select largest measurement to the nearest } \\
0.1 \mathrm{~cm} \text {; length: infant length board; weight: infant electronic weighing scales, no nappy; measured by researcher at Massey } \\
\text { University or participant home }\end{array}$ \\
\hline Demographics & Completed online by mother \\
\hline Mother diet & Pregnancy and lactation FFQ and FCQ. Completed online by mother \\
\hline $\begin{array}{l}\text { Baby eating } \\
\text { behaviour }\end{array}$ & Baby eating behaviour questionnaire [54]. Completed online by mother \\
\hline Compliance & 2-min check-in questionnaires. Completed online by mother \\
\hline
\end{tabular}

${ }^{\mathrm{a}}$ Analysed by LabTests, Auckland

${ }^{b}$ Serum ferritin, C-reactive protein (CRP), haemoglobin

$F F Q$ food frequency questionnaire, $F F Q$ food frequency questionnaire, $F C Q$ food choices questionnaire

using provided digital scales and completing the food record sheet. Estimated spills or food fallen on the bib will be recorded. The greater amount of food eaten may indicate a greater preference or acceptance for that food. In addition, the diary collects data for breast/formula milk feeding, meat consumption, and medication/supplements. Mothers can report factors that may have affected infant feeding each day (e.g. teething, unwell).

The diary is designed specifically for this study and includes a liking tool to assess the degree that infants like the study foods (see Liking tool). Combining these tools into one booklet should reduce participant burden and improve data collection. Detailed and visually appealing instructions on the feeding environment and protocol, such as food rotation and video-recorded meals, are included. Food diaries for each group differ only by the allocated foods mentioned; for example, instructions for the orange food do not feature for the intervention group diary. Week 1 and week 4 diaries also differ slightly by the removal of irrelevant instructions; for example, the week 4 diary excludes the instruction "After the first four days...". A similar 3-day weighed food diary will be provided at 9 months of age but includes the option to list any other vegetables or fruits eaten that day.

Weighed food records are considered the best estimate food intake for children aged 0.5 to 4 years [58]. The use of 4- and 3-day weighed food diaries should help to reduce participant burden that is typically associated with those of greater durations (e.g. a 7-day food diary) without compromising accuracy $[59,60]$. These durations also fit well with the protocol; for example, three tests meals offered over three consecutive days at 9 months of age is appropriately measured by a 3-day food diary.

\section{Liking tool}

The liking tool for our study is adapted from the new in-home validated elaborate method to assess infant liking of vegetables [41]. The tool asks mothers to use a form to report positive and negative behaviours for each spoon offered for the first nine spoons in their home environment, then rate how much they thought their infant liked the food after each triplet of spoons (i.e. $3 \times 3$ spoons), then again at the end of the meal. After piloting the tool with a small group of New Zealand mothers and with further expert consultation it was agreed that a pictorial 5 -point liking scale $(1=$ dislikes very much to 5 $=$ likes very much), and a list 10 positive and 10 negative behaviours per spoon, which mothers can tick as they occur would reduce participant burden. The greater percentage of positive behaviours recorded may indicate greater liking, while an average score of at least 4 on the liking scale should indicate that the food is liked. It is required that a researcher provides 


\begin{tabular}{|c|c|c|c|c|c|c|c|}
\hline \multirow[b]{3}{*}{ TIMEPOINT } & \multicolumn{7}{|c|}{ STUDY PERIOD } \\
\hline & \multirow{2}{*}{$\frac{\text { Enrolment }}{-t_{1}}$} & \multirow{2}{*}{$\frac{\text { Allocation }}{0}$} & \multicolumn{5}{|c|}{ Post-allocation } \\
\hline & & & $t_{\text {baseline }}$ & $t_{4 w}$ & $t_{m}$ age & $t_{12 m \text { age }}$ & $t_{24 m \text { age }}$ \\
\hline \multirow{2}{*}{$\begin{array}{l}\text { ENROLMENT: } \\
\text { Eligibility screen }\end{array}$} & & & & & & & \\
\hline & $\mathrm{X}$ & & & & & & \\
\hline Informed consent & $\mathrm{x}$ & & & & & & \\
\hline Allocation & & $\mathrm{X}$ & & & & & \\
\hline \multirow{4}{*}{$\begin{array}{l}\text { INTERVENTIONS: } \\
\text { Vegetables only } \\
\text { (intervention) } \\
\text { Fruit and vegetables } \\
\text { (control) }\end{array}$} & & & & & & & \\
\hline & & & 4 & & & & \\
\hline & & & & & & & \\
\hline & & & $\bullet$ & & & & \\
\hline \multicolumn{8}{|l|}{$\begin{array}{l}\text { ASSESSMENTS } \\
\text { Primary outcome }\end{array}$} \\
\hline \multicolumn{8}{|l|}{$\begin{array}{l}\text { Vegetable intake } \\
\text { Weighed food diary }\end{array}$} \\
\hline \multicolumn{8}{|l|}{ Secondary outcomes } \\
\hline \multicolumn{8}{|l|}{$\begin{array}{l}\text { Vegetable liking } \\
\text { Liking tool }\end{array}$} \\
\hline \multicolumn{8}{|l|}{$\begin{array}{l}\text { Vegetable wanting } \\
\text { Rate of acceptance } \\
\text { (video-recording) }\end{array}$} \\
\hline \multicolumn{8}{|l|}{$\begin{array}{l}\text { Total vegetable intake } \\
F F Q\end{array}$} \\
\hline \multicolumn{8}{|l|}{$\begin{array}{l}\text { Total vegetable liking } \\
\text { Child Liking } Q\end{array}$} \\
\hline \multicolumn{8}{|l|}{ Other measures } \\
\hline Demographics & & & $\mathrm{X}$ & & & & \\
\hline $\begin{array}{l}\text { Mothers' diet } \\
\text { Preg/lact } F F Q / F C Q\end{array}$ & & & $\mathrm{X}$ & & & & \\
\hline $\begin{array}{l}\text { Baby eating behavior } \\
B E B Q\end{array}$ & & & $\mathrm{X}$ & & & & \\
\hline Compliance diary & & & $\leftrightarrow$ & & $\longrightarrow$ & & \\
\hline Infant iron studies & & & $\bullet$ & & $\longrightarrow$ & & \\
\hline Infant vitamin D & & & $\mathrm{x}$ & & & & \\
\hline \multicolumn{8}{|l|}{ Infant stool sample } \\
\hline Mother iron/vitamin D & & & $\mathrm{X}$ & & & & \\
\hline
\end{tabular}

Fig. 3 Schedule of enrolment, interventions, and assessments. According to the SPIRIT statement: Defining Standard Protocol Items for Clinical Trials. $t$, timeline; $w$, week; $F F Q$, food frequency questionnaire; preg, pregnancy; lact, lactation; $F C Q$, food choices questionnaire; $Q$, questionnaire

mothers with additional guidance on feeding environment, feeding style to adopt, when to terminate the meal (three consecutive refusals), and the list of cues related to liking/disliking. These are adapted to align with New Zealand infant feeding guidelines [1], for example, the instruction to minimise verbal communication during feeding is removed as this conflicts with recommendations to interact with and talk to the child at meal times.

\section{Video coding tool}

During the intervention, mothers will be asked to video record their infant trying each study food at home for the first time in week 1 , then again in week 4 without the researcher present. This provides a total of eight videos. When infants turn 9 months old, mothers will video record their infant at home trying meal $\mathrm{A}, \mathrm{B}$, and $\mathrm{C}$. Each participant will be given access to their own secure online shared OneDrive file to upload their videos. To 


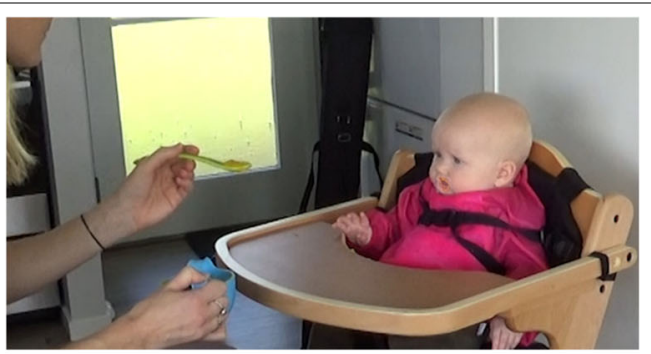

\section{Early acceptance (score 3 )}

Opens mouth when spoon is at least 1 spoons length away or grabs spoon to self-feed

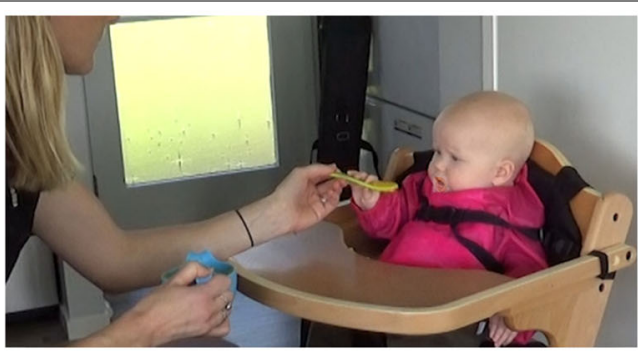

Late acceptance (score 2)

Opens mouth when spoon is less than a spoons length away

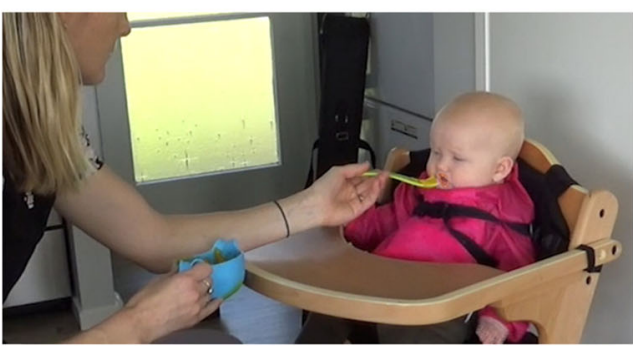

Enforced (score 1)

Opens mouth when spoon

touches lips

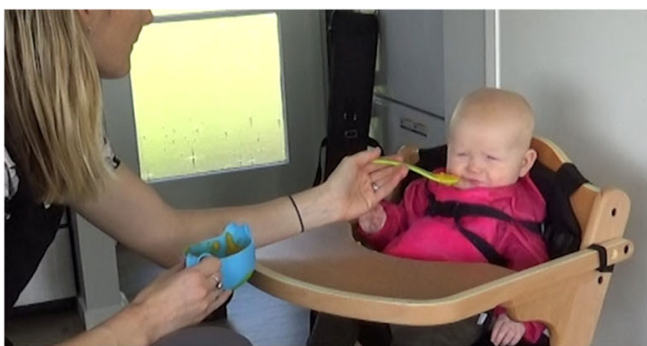

Refused (score 0)

Did not open mouth, kept mouth shut, turned head away/pushed spoon away

Fig. 4 Video coding for rate of acceptance. Images provided with written permission from the participating subjects

assess rate of acceptance, the videos will be coded using the coding tool described in Fig. 4. Rate of acceptance is the judgement made on how readily the infant accepts the spoon offered and is a measure of wanting. This outcome measure will be included because liking (hedonic drive) and wanting (motivation to eat) are considered interconnected components of food reward and pleasure but can be measured separately [61-63]. The coding tool is based on prior studies [40, 64], but with further consultation with the researchers, the addition of "grabs spoon to self-feed" as an indicator of early acceptance, as well measurable spoon distances are included to improve accuracy and standardisation. Coding will be completed by an independent researcher to reduce bias.

\section{Questionnaires}

A total of nine online questionnaires specifically developed for this study are to be completed by mothers via the survey software tool Qualtrics ${ }^{\mathrm{Tn}}$. Researchers will check all answers for completeness.

\section{Eligibility questionnaire}

A 5-min eligibility questionnaire ensures that only infants that meet the inclusion criteria will be included. 


\section{Demographics questionnaire}

A 10-min demographics questionnaire collects information at baseline on mother and infant date of birth, ethnicity, medical history, geographical location, mothers' education level, and parity.

\section{Pregnancy/lactation food frequency questionnaire (FFQ) and food choices questionnaire (FCQ)}

As the mother's diet may predict infant liking and intake of vegetables, a FFQ asking about mothers' intake of vegetables and fruit during pregnancy and lactation is adapted from an existing New Zealand validated FFQ [65]. An accompanying FCQ gains further insight on other dietary habits, such as foods avoided. These questionnaires are peer-reviewed by three experts in the nutrition and dietetics field and pilot tested with 14 new mothers. Their feedback informed minor wording changes to increase readability and acceptability, thus improving content validity; each questionnaire requires 15-20 min to complete at baseline.

\section{Food frequency questionnaire (FFQ) [66]}

An abbreviated online version of a validated complementary feeding food frequency questionnaire for mothers to complete in about 15 min when infants are 9, 12, and 24 months old collects data on infants' vegetable intake and variety. The questionnaire is abbreviated because only items relating to vegetables, fruit, and meat and alternatives are included to meet study objectives and reduce participant burden. Additional items relating to milk feeding history are added for the purpose of this study. The tool asks mothers to enter the total number of times and typical amount of a specified food (e.g. "Beans and peas") eaten by the infant in the last 4 days using free text. Check boxes are used for milk feeding items. The data will be interpreted so that the greater variety and frequency of a vegetable observed, the greater intake of that vegetable. As the tool is validated to assess nutrient intake in infants, this data may be useful for further analysis of nutrient intakes when following a "vegetables first" approach to complementary feeding.

\section{Fruit and vegetable liking questionnaire}

An online child vegetable and fruit liking questionnaire for mothers to complete when infants are 9, 12, and 24 months old collects data on vegetables and fruits tried and liked. It features visually appealing images and the same liking scale used in the adapted infant liking tool. Scores of 4 or above indicate a greater liking for the food. Content validity is confirmed by four experts in the nutrition and dietetic field and five mothers not participating in the study. To improve completion, the questionnaire is divided into two online questionnaires, with one focusing on vegetables and the other on fruit; the estimated completion time is $10 \mathrm{~min}$ each.

\section{Baby Eating Behaviour Questionnaire (BEBQ)}

As infant feeding behaviour characteristics could impact results, an online version of the validated BEBQ is to be completed [54]. This is an 18-item questionnaire with 17 items measuring four aspects of infant feeding behaviour and one item measuring general appetite before starting complementary feeding. Response options range from never $=1$ to always $=5$. Scoring involves calculating mean scores for each subscale with higher mean scores indicating greater presence of the feeding behaviour. The four themes are enjoyment of food (e.g. My baby seems contented while feeding), food responsiveness (e.g. My baby frequently wants more milk than I provide), slowness in eating (e.g. My baby takes more than $30 \mathrm{~min}$ to finish feeding), and satiety responsiveness (e.g. My baby get full up easily). This questionnaire should take $10 \mathrm{~min}$ to complete. It is expected that infants who enjoy food less, are less food responsive, eat slower, are less sensitive to internal cues of satiety, and have a smaller overall appetite may be more difficult to feed and perhaps less willing to accept vegetables specifically, compared to infants with the opposite traits.

\section{Compliance to study protocol}

A 2-min check-in compliance questionnaire collects data on how many days the intervention food was offered, other food or drink consumed other than provided in the study, medications, and factors that may affect infant feeding (e.g. teething). This will be emailed to participants on the completion of each intervention week. Mothers will be contacted by email or telephone at 9-, 12- and 24-month follow-ups and an e-card will be sent on child birthdays to improve sample retention. Mothers will receive a personalised baby bag, kitchen scales, visually appealing infant feeding resources, and petrol vouchers at no cost to them in order to improve participation rates. The video footage from mothers' first video recordings will be checked for compliance and quality, with corrections (e.g. lighting, camera angle, environment) administered by the researcher as required.

\section{Website}

A study website is designed for participants to use when wishing to register, complete the eligibility questionnaire, learn more about the study, contact the researchers, and access exclusive infant resources. The use of a New Zealand website domain, the Massey University logo, and a visually appealing study banner may improve credibility and recruitment. The website acts as a platform for distributing participant education and resources, including seven videos, three downloadable 
fridge magnets, a food safety flyer, and three meat purée recipe cards with accompanying videos. These are based on Ministry of Health infant feeding guidelines and created using design software (Canva, Photoshop, and Adobe Premier Pro). Images and video content are obtained from a photography/video shoot with written consent from the participating subjects, purchased from Shutterstock $^{\ominus}$ or taken from Creative Commons. Using online surveys, each infant feeding resource is peerreviewed by six experts in infant nutrition and 20 mothers. Feedback informed revisions; for example, it was recommended to use brighter colours for the recipe cards to improve engagement.

\section{Adverse events}

In the rare case that an allergic reaction to the infant foods, participants will be instructed to stop feeding the food and may withdraw from the trial and provided a referral to a doctor. Reports of gastrointestinal symptoms or other side effects will be further investigated by the trial registered Dietitian and the infant's health will be monitored closely for the duration of the intervention. If the adverse event persists, withdrawal from the trial and/or a referral to a doctor for further investigation is expected. All adverse events will be recorded, and mothers offered telephone/email support. If the participant needs to make a claim to Accident Compensation Corporation (ACC) due to an adverse event and the claim is not accepted, then the researcher will initiate processes to ensure they receive appropriate compensation.

\section{Blood sampling, stool collection, and analysis}

As part of screening for and monitoring infant health and iron status, capillary blood samples will be taken from infants by a registered phlebotomist using a standard "heel prick" test at baseline, after the intervention, and at the 9-month follow-up. The focus on monitoring iron status reflects concerns for meeting iron requirements during the complementary feeding period [24], with iron deficiency having consequences that are more serious and irreversible than in adults [1, 67]. Thus, serum will be used for the analysis of serum ferritin and C-reactive protein (CRP) at LabTests (Auckland). Haemoglobin will be measured using HemoCue in our HNRU laboratory. If Haemoglobin is $<110 \mathrm{~g} / \mathrm{L}$, the participant will be notified and given a referral letter to see their doctor.

Additional blood and stool collection will be taken in the interest of future research. At baseline, venous blood samples will be collected from mothers and will be stored for later analysis of iron and vitamin D. Whatman cards will collect infant serum for a future study investigating infant vitamin $\mathrm{D}$ at baseline. For microbiome research purposes, mothers will collect a stool sample from their infant before and after the 4-week intervention, then at 9,12 , and 24 months of age.

\section{Dissemination of results}

During each visit, mothers will receive their infant's growth measurements and blood haemoglobin result. The remaining blood results will be provided on request. Once available, participants who completed the intervention will receive a summary of findings in lay language, and whether they were assigned to the intervention or control. Results will be presented at national and international scientific conferences, prepared for publication in peer-reviewed journals, and circulated to the media and should be of interest to a range of audiences including families, health professionals, district health boards, academics, and primary health organisations. Individuals with substantive contributions to the design, conduct, interpretation, and reporting of the study will be recognised by granting authorship on the final relevant report.

\section{Data handling}

Name and address details will be kept in a separate Microsoft Excel spreadsheet, and will include progress check boxes in order to track and schedule follow-ups. All entries will be cross-checked by another member of the research team. The video content to be stored on the shared storage platform OneDrive will be protected by Citrus Consulting Group Limited, a high security data management and storage company in New Zealand. Only the researcher and the participant have access to the designated video folder labelled by subject number. All data will be stored safely under confidential conditions and archived for at least 5 years, and only the researchers will have access and permissions to the final intervention dataset.

\section{Statistical analysis}

Statistical analysis will be performed using IBM SPSS version 25.0 (IBM Corp. Released 2017, IBM SPSS Statistics for Windows Version 25.0. Armonk, NY, IBM Corp.). Data will be cleaned and checked for coding errors and completeness. To assess if data is normally distributed, the Kolmogorov-Smirnov and Shapiro-Wilk tests and normality plots will be used. Data that is not normally distributed will be transformed using log transformations to improve normality. Mean (standard deviation) and median (25, 27 percentiles) will be used to report normal and non-normal data, respectively. Transformed data will be reported at geometric mean (95\% CI) following back transformation, and categorical data as frequencies.

Baseline characteristics of infants and mothers will be compared across intervention groups using the 
independent $t$-test or Mann-Whitney test for continuous variables (e.g. infants' age, weight, breastfeeding duration, and mothers' age), and chi-square tests for categorical variables (e.g. gender, milk feeding type, and mothers' education).

For the primary analysis at 9 months, Independent ttest or Mann-Whitney test will be used to assess differences in vegetable intake and other food acceptance variables, depending on data distribution.

Additional analyses will be performed to investigate if the intake of intervention foods and mothers-rated liking and rate of acceptance after 4 weeks are correlated (using Pearson's or Spearman's correlations depending on data distribution).

Given the nature of the intervention, per protocol (PP) analyses will be conducted. Although this may compromise the integrity of randomisation and reduce sample size, PP should help address dilution effects of noncompliance/missing data that is associated with intention-to-treat analysis. PP may also provide more information on the efficacy of the treatment. Reasons for excluding patients (e.g. loss to follow-up, major deviations from the protocol) will be fully reported. All statistical tests will be two-tailed with an alpha value of $\mathrm{P}<$ 0.05 , and corrections applied for multiple comparisons where indicated.

\section{Discussion}

Despite the known health benefits of a diet rich in vegetables and fruit $[2,68,69]$, children's vegetable consumption remains lower than recommended worldwide [8-12]. Introducing vegetables at the beginning of complementary feeding may be a promising strategy to promote vegetable intake in children, both immediately and later in life [25]. However, the few studies that have investigated this approach vary considerably in methodology and are limited by small sample sizes, short duration, and/or poor ecological validity [33-35, 37-39]. The main purpose of this randomised controlled trial is to address this research gap by determining whether exposure to vegetables only during the first 4 weeks of complementary feeding increases later intake and liking of vegetables in infants, compared to a control group which includes both fruit and vegetables.

Strengths of this study include the randomisation of infants, longitudinal design that follows infants until 24 months of age, use of diverse and complementary methods to assess outcome measures, a relatively large sample size, improved ecological validity (e.g. conducted in the home environment for the outcomes of interest), and using a control that mimics current practice. Possible limitations include difficulties for families to adhere to study procedures and remain engaged for up to 24 months of age. Since this is a convenience sample, participants are self-selecting and likely interested in nutrition and health with the potential to generate bias in the participant recruitment. However, extensive measures have been put in place to mitigate these, such as weekly compliance questionnaires, offering home visits/ virtual meetings, providing incentives (free infant foods, petrol vouchers), and blinding mothers to the foods. In addition, time has been spent to develop a feeding protocol that is easy to follow (e.g. use of engaging colours, visual aids, and clear instructions) and facilitated by evidenced-based infant feeding support.

We anticipate that this trial will provide important insights into the cause-effect relationship between a "vegetables first" approach to complementary feeding and vegetable liking and intake in children. To our knowledge, this is the first study to investigate such causality of association in the New Zealand context. If successful, this study may help inform future updates of national and international infant feeding recommendations and lead to practical advice for caregivers and health professionals wanting to improve vegetable consumption in children.

\section{Abbreviations}

BEBQ: Baby Eating Behaviour Questionnaire; FFQ: Food Frequency

Questionnaire; FCQ: Feeding Choices Questionnaire; HNRU: Human Nutrition Research Unit

\section{Supplementary Information}

The online version contains supplementary material available at https://doi. org/10.1186/s13063-021-05374-7.

Additional file 1. Information Sheet.

Additional file 2. Consent Form.

Additional file 3. Liking Tool.

Additional file 4. SPIRIT 2013 Checklist: Recommended items to address in a clinical trial protocol and related documents*.

\section{Acknowledgements}

We are deeply grateful to all the families who have and will take part in this study, LabTests, Citrus Consulting Group Limited, and the research team, which includes volunteers, phlebotomists, speech and language therapist, research scientists, and trial manager. We would also like to acknowledge the previous research and advice from Sophie Nicklaus and Kameron Moding.

\section{Trial status}

Issue date: 22 September 2020

Protocol amendment number: Original

First participant recruited on 16 May 2019. Recruitment completed on 4 March 2020. The protocol has been submitted after the end of recruitment given the nature of participant blinding.

\section{Authors' contributions}

CC and PRvH conceived and supervised the study. CC, PRvH, and JR initiated the study design, acquired funding, and ethics approval. MH provided additional review and input for the study design before implementation. JR coordinated the development and manufacture of infant foods and administered the intervention. JR drafted and wrote the manuscript; designed infant feeding resources, food diaries, liking tool, online questionnaires, and website; and has coordinated recruitment, participant 
management, and data collection. JR is conducting the primary statistical analysis. All authors contributed to refinement of the study protocol and approved the final manuscript.

\section{Funding}

Funding for the study has been provided by the New Zealand Lottery Board (Lottery Health Grant) and Massey University Post Graduate Research support grant. This funding covers the run-in and material costs for the trial to follow 120 participants for the duration of the study. Material costs include infant foods, infant feeding resources, petrol vouchers, study website, and blood analysis. Citrus Consulting Group Limited has sponsored data management and security services for video content. There has been contribution in the form of a Massey Vice Chancellor's Doctoral Scholarship to support the PhD candidate running the trial. The design, management, analysis, and reporting of the study are entirely independent of the manufacturers of the infant foods and sponsors.

\section{Availability of data and materials}

Data and tools will be made available on request and in accordance with the ethics approval for the study.

\section{Declarations}

\section{Ethics approval and consent to participate}

Ethical approval was granted by the Massey University Human Ethics Committee: Southern A, Application SOA 18/56. The lead researcher will send the information sheet, screen for eligibility, and gain participants' written consent under the supervisory team. If protocol changes occur, amendments to the ethics committee will be submitted, and on approval, the information sheet updated, participants informed, and trial registry updated.

The trial has been registered with the Australian New Zealand Clinical Trial Registry, ACTRN12619000737134

The trial will be reported according to the CONSORT 2010 guidelines.

\section{Consent for publication}

The authors provide consent for publication

\section{Competing interests}

The authors declare that they have no competing interests.

\section{Author details}

${ }^{1}$ School of Sport, Exercise and Nutrition, Massey University, Auckland, New Zealand. ${ }^{2}$ School of Psychology, University of Leeds, Leeds, England, UK.

\section{Received: 29 March 2021 Accepted: 15 June 2021}

Published online: 26 July 2021

\section{References}

1. Ministry of Health. Food and nutrition guidelines for healthy infants and toddlers (aged 0-2): a background paper - partially revised december 2012. 4th ed. Wellington: Ministry of Health; 2008.

2. Appleton K, Hemingway A, Saulais L, Dinnella C, Monteleone E, Depezay L, et al. Increasing vegetable intakes: rationale and systematic review of published interventions. Eur J Nutr. 2016;55(3):869-96. https://doi.org/10.1 007/s00394-015-1130-8.

3. Ledoux T, Hingle MD, Baranowski T. Relationship of fruit and vegetable intake with adiposity: a systematic review. Obes Rev. 2011;12(5):e143-e50. https://doi.org/10.1111/j.1467-789X.2010.00786.x.

4. Mellendick K, Shanahan L, Wideman L, Calkins S, Keane S, Lovelady C. Diets rich in fruits and vegetables are associated with lower cardiovascular disease risk in adolescents. Nutrients. 2018;10(2):136. https://doi.org/10.3390/ nu10020136.

5. Funtikova AN, Navarro E, Bawaked RA, Fíto M, Schröder H. Impact of diet on cardiometabolic health in children and adolescents. Nutr J. 2015;14(1):118. https://doi.org/10.1186/s12937-015-0107-z.

6. Reidy KC, Deming DM, Briefel RR, Fox MK, Saavedra JM, Eldridge AL. Early development of dietary patterns: transitions in the contribution of food groups to total energy - feeding infants and toddlers study, 2008. BMC Nutr. 2017;3(1):5. https://doi.org/10.1186/s40795-016-0124-0.
7. Mikkilä V, Räsänen L, Raitakari $O$, Pietinen P, Viikari J. Consistent dietary patterns identified from childhood to adulthood: the cardiovascular risk in Young Finns Study. Br J Nutr. 2005;93(6):923-31. https://doi.org/10.1079/ BJN20051418.

8. Miller V, Yusuf S, Chow CK, Dehghan M, Corsi DJ, Lock K, et al. Availability, affordability, and consumption of fruits and vegetables in 18 countries across income levels: findings from the Prospective Urban Rural Epidemiology (PURE) study. Lancet Glob Health. 2016;4(10):e695-703. https://doi.org/10.1016/S2214-109X(16)30186-3.

9. World Health Organization. Diet, nutrition, and the prevention of chronic diseases: report of a joint WHO/FAO expert consultation. Geneva, Switzerland: World Health Organization; 2003.

10. Ministry of Health. New Zealand Health Survey. Wellington: Ministry of Health; 2018.

11. Mihrshahi S, Myton R, Partridge SR, Esdaile E, Hardy LL, Gale J. Sustained low consumption of fruit and vegetables in Australian children: findings from the Australian National Health Surveys. Health Promot J Austr. 2019;30(1): 83-7. https://doi.org/10.1002/hpja.201.

12. Health Survey for England 2018. NHS. http://healthsurvey.hscic.gov.uk/datavisualisation/data-visualisation/explore-the-trends/fruit-vegetables.a spx?type=child (2019) Accessed 05 August 2020.

13. Bailey RL, Jun S, Eldridge AL. The 2016 feeding infants and toddlers study (fits): dietary intakes and practices of children in the United States from birth to 48 months. In: Henry CJ, Nicklas TA, Nicklaus S, editors. Nurturing a healthy generation of children: research gaps and opportunities. 91. Switzerland: Karger Publishers; 2019. p. 99-109. https://doi.org/10.1159/0004 93701.

14. Harris HA, Staton S, Morawska A, Gallegos D, Oakes C, Thorpe K. A comparison of maternal feeding responses to child fussy eating in lowincome food secure and food insecure households. Appetite. 2019;137:25966. https://doi.org/10.1016/j.appet.2019.03.005.

15. Pearson N, Biddle SJ, Gorely T. Family correlates of fruit and vegetable consumption in children and adolescents: a systematic review. Public Health Nutr. 2009;12(2):267-83. https://doi.org/10.1017/\$1368980008002 589.

16. Forestell CA. Flavor perception and preference development in human infants. Ann Nutr Metab. 2017;70(Suppl. 3):17-25. https://doi.org/10.1159/ 000478759 .

17. Wardle J, Cooke L. Genetic and environmental determinants of children's food preferences. Br J Nutr. 2008;99(S1):S15-21. https://doi.org/10.1017/ S000711450889246X.

18. Mennella J, Bobowski NK. The sweetness and bitterness of childhood: insights from basic research on taste preferences. Physiol Behav. 2015;152(Pt B):502-7. https://doi.org/10.1016/j.physbeh.2015.05.015.

19. Zaçe D, Di Pietro ML, Caprini F, de Waure C, Ricciardi W. Prevalence and correlates of food insecurity among children in high-income European countries. A systematic review. Ann Ist Super Sanita. 2020;56(1):90-8. https:// doi.org/10.4415/ANN_20_01_13.

20. Van Lancker W, Parolin Z. COVID-19, school closures, and child poverty: a social crisis in the making. Lancet Public Health. 2020;5(5):e243-e4. https:// doi.org/10.1016/S2468-2667(20)30084-0.

21. Food security in the United States. United States Department of Agriculture. https://www.ers.usda.gov/topics/food-nutrition-assistance/food-security-inthe-us/interactive-charts-and-highlights/ (2019) Accessed 05 August 2020.

22. Ministry of Health. Household food insecurity among children: New Zealand Health Survey. Wellington; 2019.

23. Schlichting D, Hashemi L, Grant C. Infant food security in New Zealand: a multidimensional index developed from cohort data. Int J Env Res Pub He. 2019;16(2):283. https://doi.org/10.3390/ijerph16020283.

24. Chambers L, Hetherington M, Cooke L, Coulthard H, Fewtrell M, Emmett $P$, Lowdon J, Blissett J, Lanigan J, Baseley C, Stanner S. Reaching consensus on a 'vegetables first' approach to complementary feeding. Nutr Bull. 2016; 41(3):270-6. https://doi.org/10.1111/nbu.12220.

25. Barends C, Weenen $\mathrm{H}$, Warren J, Hetherington MM, de Graaf C, de Vries JH. A systematic review of practices to promote vegetable acceptance in the first three years of life. Appetite. 2019;137:174-97. https://doi.org/10.1016/j.a ppet.2019.02.003.

26. Hendrie GA, Lease HJ, Bowen J, Baird DL, Cox DN. Strategies to increase children's vegetable intake in home and community settings: a systematic review of literature. Matern Child Nutr. 2017;13(1):e1227610. https://doi. org/10.1111/mcn. 12276 . 
27. Mennella J, Turnbull B, Ziegler PJ, Martinez $\mathrm{H}$. Infant feeding practices and early flavor experiences in Mexican infants: an intra-cultural study. J Am Diet Assoc. 2005;105(6):908-15. https://doi.org/10.1016/j.jada.2005.03.008.

28. Miles G, Siega-Riz AM. Trends in food and beverage consumption among infants and toddlers: 2005-2012. Pediatrics. 2017;139(6):e20163290. https:// doi.org/10.1542/peds.2016-3290.

29. Bakke AJ, Carney EM, Higgins MJ, Moding K, Johnson SL, Hayes JE. Blending dark green vegetables with fruits in commercially available infant foods makes them taste like fruit. Appetite. 2020;150:104652. https://doi.org/10.101 6/j.appet.2020.104652.

30. Moding KJ, Ferrante MJ, Bellows LL, Bakke AJ, Hayes JE, Johnson SL. Variety and content of commercial infant and toddler vegetable products manufactured and sold in the United States. Am J Clin Nutr. 2018;107(4): 576-83. https://doi.org/10.1093/ajen/nqx079.

31. Baby food: Wattie's for baby. Heinz Wattie's. https://www.forbaby.co.nz/Ba by-Foods-Products/Baby-Food-Wattie-s-for-Baby (n.d.) Accessed 05 August 2020.

32. Fu X, Conlon CA, Haszard JJ, Beck KL, von Hurst PR, Taylor RW, et al. Food fussiness and early feeding characteristics of infants following baby-led weaning and traditional spoon-feeding in New Zealand: an internet survey. Appetite. 2018;130:110-6. https://doi.org/10.1016/j.a ppet.2018.07.033.

33. Hetherington MM, Schwartz C, Madrelle J, Croden F, Nekitsing C, Vereijken $\mathrm{CM}$, et al. A step-by-step introduction to vegetables at the beginning of complementary feeding. The effects of early and repeated exposure. Appetite. 2015;84:280-90. https://doi.org/10.1016/j.appet.2014.1 0.014

34. Barends C, de Vries J, Mojet J, de Graaf C. Effects of repeated exposure to either vegetables or fruits on infant's vegetable and fruit acceptance at the beginning of weaning. Food Qual Prefer. 2013;29(2):157-65. https://doi. org/10.1016/j.foodqual.2013.03.008.

35. Barends C, de Vries JH, Mojet J, de Graaf C. Effects of starting weaning exclusively with vegetables on vegetable intake at the age of 12 and 23 months. Appetite. 2014:81:193-9. https://doi.org/10.1016/j.appet.2014.06.023.

36. Fildes A, Lopes C, Moreira P, Moschonis G, Oliveira A, Mavrogianni C, et al. An exploratory trial of parental advice for increasing vegetable acceptance in infancy. Br J Nutr. 2015;114(2):328-36. https://doi.org/10.1017/S000711451 5001695.

37. Gerrish CJ, Mennella JA. Flavor variety enhances food acceptance in formula-fed infants. Am J Clin Nutr. 2001;73(6):1080-5. https://doi.org/10.1 093/ajcn/73.6.1080.

38. Maier A, Chabanet C, Schaal B, Leathwood P, Issanchou S. Breastfeeding and experience with variety early in weaning increase infants' acceptance of new foods for up to two months. Clin Nutri. 2008;27(6):849-57. https://doi. org/10.1016/j.clnu.2008.08.002.

39. Maier-Nöth A, Schaal B, Leathwood P, Issanchou S. The lasting influences of early food-related variety experience: a longitudinal study of vegetable acceptance from 5 months to 6 years in two populations. PLoS One. 2016; 11(3):e0151356. https://doi.org/10.1371/journal.pone.0151356.

40. Hetherington M, Madrelle J, Nekitsing C, Barends C, de Graaf C, Morgan S, et al. Developing a novel tool to assess liking and wanting in infants at the time of complementary feeding-The Feeding Infants: Behaviour and Facial Expression Coding System (FIBFECS). Food Qual Prefer. 2016;48:238-50. https://doi.org/10.1016/j.foodqual.2015.09.010.

41. Madrelle J, Lange C, Boutrolle I, Valade O, Weenen H, Monnery-Patris S, et al. Development of a new in-home testing method to assess infant food liking. Appetite. 2017;113:274-83. https://doi.org/10.1016/j.appet.2017.03.002

42. Scientific Advisory Committee on Nutrition. Feeding in the first year of life: SACN report. 2018.

43. What to feed your baby. NHS. https://www.nhs.uk/start4life/weaning/whatto-feed-your-baby/around-6-months/ (n.d.) Accessed 05 August 2020.

44. Lind $T$, Johansson $U$, Ohlund I, Lindberg L, Lonnerdal B, Tennefors $C$, et al. Study protocol: optimized complementary feeding study (OTIS): a randomized controlled trial of the impact of a protein-reduced complementary diet based on Nordic foods. BMC Public Health. 2019;19(1): 134. https://doi.org/10.1186/s12889-019-6466-1.

45. van der Veek S, de Graaf C, de Vries J, Jager G, Vereijken C, Weenen H, et al. Baby's first bites: a randomized controlled trial to assess the effects of vegetable-exposure and sensitive feeding on vegetable acceptance, eating behavior and weight gain in infants and toddlers. BMC Pediatr. 2019;19(1): 266. https://doi.org/10.1186/s12887-019-1627-z.
46. Stang A. Randomized controlled trials - an indispensible part of clinical research. Deutsches Ärzteblatt International. 2011;108(39):661-2. https://doi. org/10.3238/arztebl.2011.0661.

47. Spieth PM, Kubasch AS, Penzlin Al, Illigens BM-W, Barlinn K, Siepmann T Randomized controlled trials-a matter of design. Neuropsychiatr Dis Treat. 2016;12:1341-49. https://doi.org/10.2147/NDT.S101938.

48. Harris $\mathrm{G}$, Mason S. Are there sensitive periods for food acceptance in infancy? Curr Nutr Rep. 2017;6(2):190-6. https://doi.org/10.1007/s13668-0170203-0.

49. Massey University. Veges First Study. https://www.vegesfirststudy.co.nz/ (2020) Accessed 10 July 2020.

50. Fox N, Hunn A, Mathers N. Sampling and sample size calculation: Research Design Service for the East Midlands/Yorkshire \& the Humber; 2009.

51. Births and deaths: year ended December 2018. Stats NZ. https://www.stats. govt.nz/information-releases/births-and-deaths-year-ended-december-2018 (2019). Accessed 05 August 2020

52. Ministry of Health. Eating for healthy babies and toddlers/Ngā kai tōtika mō te hunga kōhungahunga. New Zealand: Ministry of Health; 2013.

53. Beef and Lamb New Zealand. Fuelled by iron: practical tips and easy ironrich meals ideas for babies and toddlers. New Zealand: Beef and Lamb New Zealand; 2018.

54. Llewellyn $\mathrm{CH}$, van Jaarsveld $\mathrm{CH}$, Johnson L, Carnell S, Wardle J. Development and factor structure of the Baby Eating Behaviour Questionnaire in the Gemini birth cohort. Appetite. 2011;57(2):388-96. https://doi.org/10.1016/j.appet.2011.05.324.

55. Coulthard $H$, Harris $G$, Fogel A. Exposure to vegetable variety in infants weaned at different ages. Appetite. 2014;78:89-94. https://doi.org/10.1016/ j.appet.2014.03.021.

56. Maier A, Chabanet C, Schaal B, Issanchou S, Leathwood P. Effects of repeated exposure on acceptance of initially disliked vegetables in 7-month old infants. Food Qual Prefer. 2007;18(8):1023-32. https://doi.org/10.1016/j. foodqual.2007.04.005.

57. Remy E, Issanchou S, Chabanet C, Nicklaus S. Repeated exposure of infants at complementary feeding to a vegetable purée increases acceptance as effectively as flavor-flavor learning and more effectively than flavor-nutrient learning. J Nutr. 2013;143(7):1194-200. https://doi.org/10.3945/jn.113.175646.

58. Burrows TL, Martin RJ, Collins CE. A systematic review of the validity of dietary assessment methods in children when compared with the method of doubly labeled water. J Am Diet Assoc. 2010;110(10):1501-10. https://doi. org/10.1016/j.jada.2010.07.008.

59. Davies PS, Coward W, Gregory J, White A, Mills A. Total energy expenditure and energy intake in the pre-school child: a comparison. Br J Nutr. 1994; 72(1):13-20. https://doi.org/10.1079/BJN19940005.

60. Thompson FE, Subar AF. Dietary assessment methodology. Nutrition in the Prevention and Treatment of Disease: Elsevier; 2017. p. 5-48, https://doi. org/10.1016/B978-0-12-802928-2.00001-1.

61. Berridge KC. Food reward: brain substrates of wanting and liking. Neurosci Biobehav Rev. 1996;20(1):1-25. https://doi.org/10.1016/01497634(95)00033-B

62. Berridge KC, Ho C-Y, Richard JM, DiFeliceantonio AG. The tempted brain eats: pleasure and desire circuits in obesity and eating disorders. Brain Res. 2010;1350:43-64. https://doi.org/10.1016/j.brainres.2010.04.003.

63. Nicklaus $\mathrm{S}$. The role of food experiences during early childhood in food pleasure learning. Appetite. 2016;104:3-9. https://doi.org/10.1016/j.appet.201 5.08.022.

64. Nekitsing C, Madrelle J, Barends C, de Graaf C, Parrott H, Morgan S, et al. Application and validation of the Feeding Infants: Behaviour and Facial Expression Coding System (FIBFECS) to assess liking and wanting in infants at the time of complementary feeding. Food Qual Prefer. 2016;48:228-37. https://doi.org/10.1016/j.foodqual.2015.09.012.

65. Beck KL, Kruger R, Conlon CA, Heath A-LM, Coad J, Matthys C, et al. The relative validity and reproducibility of an iron food frequency questionnaire for identifying iron-related dietary patterns in young women. J Acad Nutr Diet. 2012;112(8):1177-87. https://doi.org/10.1016/j. jand.2012.05.012.

66. Judd A, Beck K, McKinlay C, Conlon C. Determining the validity and reproducibility of a feeding assessment tool to assess nutrient intake in New Zealand infants aged 9 to 12 months. Proceedings. 2019;8(1):53. https://doi.org/10.3390/proceedings2019008053.

67. World Health Organization. Complementary feeding: report of the global consultation, and summary of guiding principles for complementary 
feeding of the breastfed child. Geneva, Switzerland: World Health Organization; 2003.

68. Wallace TC, Bailey RL, Blumberg JB, Burton-Freeman B, Chen CO, CroweWhite $\mathrm{KM}$, et al. Fruits, vegetables, and health: a comprehensive narrative, umbrella review of the science and recommendations for enhanced public policy to improve intake. Crit Rev Food Sci Nutr. 2020;60:1-38. https://doi. org/10.1080/10408398.2019.1632258.

69. Boeing H, Bechthold A, Bub A, Ellinger S, Haller D, Kroke A, et al. Critical review: vegetables and fruit in the prevention of chronic diseases. Eur J Nutr. 2012;51(6):637-63. https://doi.org/10.1007/s00394-012-0380-y.

\section{Publisher's Note}

Springer Nature remains neutral with regard to jurisdictional claims in published maps and institutional affiliations.

Ready to submit your research? Choose BMC and benefit from:

- fast, convenient online submission

- thorough peer review by experienced researchers in your field

- rapid publication on acceptance

- support for research data, including large and complex data types

- gold Open Access which fosters wider collaboration and increased citations

- maximum visibility for your research: over $100 \mathrm{M}$ website views per year

At BMC, research is always in progress.

Learn more biomedcentral.com/submissions 